\title{
Medium-Term Budgetary Framework for Fiscal Efficiency: A Conceptual Analysis of Bangladesh Case
}

\author{
Md. Sanwar Jahan Bhuiyan, Ph D \\ Director (Planning, Programming \& Recording) \\ Bangladesh Public Administration Training Centre, Dhaka, Bangladesh \\ E-mail: sanwarsamia@gmail.com
}

Mst. Shumshunnahar (Corresponding author)

Assistant Professor, Department of Public Administration

Comilla University, Bangladesh

E-mail: snaharh@gmail.com

Received: Nov. 4, 2018 Accepted: Nov. 26, 2018 Online published: Nov. 30, 2018

doi:10.5296/jpag.v8i4.13850 URL: https://doi.org/10.5296/jpag.v8i4.13850

\begin{abstract}
Medium-Term Budgetary Framework (MTBF) is one of the most important policy reforms in the fiscal management of both developing and developed countries of the world. Over the last two decades, on advocacy and technical assistance of World Bank and IMF more than 132 countries of the globe successfully implemented this new form of performance-based budgetary mechanism. As a part of public finance management reform, Bangladesh first introduced MTBF in 2004 and piloted the process for FY 2005-2006 in four ministries successfully. From the FY 2011-12 MTBF has already been rolled out to all ministries and agencies of Bangladesh. The paper discusses the conceptual framework of MTBF that has been following in Bangladesh along with a very limited discussion of empirical evidence of achieving fiscal efficiency by some developing countries. The paper is based on secondary data. On reviewing the relevant literature, it is found that the MTBF mechanism is scientifically devised and logically organized where achieving fiscal discipline, allocative and operational efficiency are the main focus of it. The paper also explored that the new form of a budgetary framework is a radical shift from traditional and compliance-based budgetary system to performance-based, result-oriented, priority-focused budgetary mechanism. Finally, the paper places some empirical evidence on fiscal discipline, allocative and operational
\end{abstract}


efficiency that has been achieved by MTBF or MTEF-adopting countries.

Keywords: Bangladesh, medium-term budgetary framework, fiscal efficiency, fiscal discipline, allocative efficiency, operational efficiency

\section{Introduction}

Public budget is one of the important instruments of overall fiscal management of a country. It is a financial plan of mobilizing and allocating financial resources for achieving fiscal targets of an economy. It is also regarded as a financial statement of estimated receipts and expenditure for a period, traditionally for a year. It is also seen as a financial reflection of government's annual plan - a statement of what a government wants to do within a period of time. In other sense, it is a financial mirror of public policies and also is used as a powerful instrument for managing economic resources of the country. The budget of a particular financial year is also a legal instrument since it is a bill passed in parliament and duly signed by the President of the Republic. Since 2004, the Government of Bangladesh introduced a new structure in the budgetary mechanism which is completely a paradigm shift from the traditional approach to an output based modern approach. The new approach is then called the Medium Term Budgetary Framework (MTBF).

\section{Objectives of the Study}

The purpose of the study is to make a critical analysis of the Medium-Term Budgetary Framework employed in all Ministries and divisions of Bangladesh. The specific objectives of the study were to make an exhaustive analysis of nature and features of MTBF in Bangladesh; to analyze the different types of efficiencies of MTBF in Bangladesh; and finally, to examine the empirical evidence of the successful operation of MTBF in different countries of the world.

\section{The Methodology of the Study}

The study has been carried out following desk study method. Secondary literature, such as reports, monographs, research articles, and other empirical information was collected and analyzed to obtain the research objectives. The conceptual and theoretical findings were validated and concluded with empirical evidence from various research reports.

\section{Concepts of Medium-Term Budgetary Framework}

The medium Term Budgetary Framework (MTBF) is a multi-year approach of budgeting that ascertains medium-term plans and targets for aggregate receipts and expenditures. The special features of MTBF are; first, it deliberately links expenditure plan to policy objectives of government (Ministry of Finance, 2005. p.01); second, it makes a reliable estimate of financial resources to be available for expenditure (Ministry of Finance, 2005. p.01); third, it allows a reasonable autonomy to line ministries and agencies to propose their budget by themselves and links organizational performance with budgetary allocation (Ministry of Finance, 2005. p.02). The MTBF approach distinguishes itself from the traditional approach of the budget by including upcoming financial year's annual budget along with rolling estimate and projection of the following three years. 


\section{Macrothink}

In Bangladesh, MTBF is the generic title of the approach of multi-year budgeting whereas some countries took the title MTEF to denote the same. World Bank documents explained the whole process under incrementally demanding following three stages (World Bank, 2013. p.18).

\subsection{MTFF-Medium Term Fiscal Framework}

It is an upstream macro-economic structure from where MTBF gets mid-term indications about its aggregate resource envelope. In Bangladesh, it is called Medium-Term Macroeconomic Framework (MTMF). MTFF is a tool for checking the consistency of assumptions or projections concerning GDP growth, tax-GDP ratio, fiscal deficit, foreign aids and borrowing possibility, the balance of payments, exchange rate, inflation, credit growth and the share of the public and private savings and investments etc. Under this top-down framework impact of associated risks and sustainability of flow of economic growth are being generally assessed.

\subsection{MTBF-Medium Term Budgetary Framework}

MTBF is a mechanism to reconcile actual resource demand of line-ministries (includes implementing agencies) with available resource envelope which has been ascertained on the basis of MTFF or MTMF (in Bangladesh it is called Medium-Term Macroeconomic Framework). In the MTBF phase, the line ministries and agencies are asked to prepare their current year's budget with forthcoming three years projection along with estimated outputs and outcomes linking with strategic goals of the organization. The main focus of this phase is to examine and confirm performance targets and required resources for attaining those targets.

\subsection{MTPF-Medium Term Performance Framework}

It the matured stage of mid-term budgetary framework where the shift of focus from input to output has to be done (World Bank, 2013. p.19). It ensures measurement and evaluation of the performance of the line ministries and implementing agencies. It does not encourage only performance but ensures strategic linkage between input and output; measures the performance of organizations and also facilitates to maintain efficiency in the implementation of the budget.

\section{Global Trend of MTBF/MTEF Adoption}

As of the end of 2008, 132 countries of the world introduced MTEF or MTBF or other similar mid-term budgetary frameworks for managing public fund (World Bank, 2013. p.24). From the World Bank Report (2013) it is reported that in 2008, 71 countries adopted MTFF, 42 adopted MTBF and 19 adopted MTPF (Table-1). 
Table 1. Global Trend of Adoption of MTBF/MTEF.

\begin{tabular}{c|c|c|c|c|c}
\hline \multirow{2}{*}{ Stage } & \multicolumn{2}{|c|}{ Number of MTBFs } & \multicolumn{3}{c}{ Change, 1990-2008 } \\
\cline { 2 - 6 } & $\mathbf{1 9 9 0}$ & $\mathbf{2 0 0 8}$ & New MTEFs & Transitions & Reversals \\
\hline MTFF & 9 & 71 & 104 & -41 & -1 \\
\hline MTBF & 1 & 42 & 21 & 23 & -3 \\
\hline MTPF & 1 & 19 & 0 & 18 & 0 \\
\hline $\begin{array}{c}\text { Total } \\
\text { MTEF/MTBF }\end{array}$ & 11 & 132 & 125 & 0 & -4 \\
\hline
\end{tabular}

Source: World Bank, 2013

\section{The Linkage between MTBF and MTMF}

In Bangladesh, Medium Term Budgetary Framework is generally influenced by another upstream macroeconomic framework which is known to MTMF. Medium-Term Macroeconomic Framework (MTMF) is an upstream macroeconomic structure from where MTBF gets indications on its resources envelope. MTMF is a tool for checking the consistency of assumptions or projections concerning economic growth, the fiscal deficit, the balance of payments, the exchange rate, inflation, credit growth, monetary development and the share of the public and private investments etc. (Finance Division. p.04) The main purpose of the MTMF is to assess the economic and fiscal sustainability in alternative macroeconomic policy scenarios and the impact of the risks associated with each of these scenarios. With regard to the MTBF, it also provides a method to determine the Government's 'resource envelope' which will be applied in the preparation of budget estimates at Line Ministry level.

Formulating and articulating the statement of Medium Term Strategic Objectives (MTSO) of line ministries in terms of intended outcome to be achieved within the medium-term period is an important component of MTMF. The Medium Term Strategic Objectives (MTSO) must have linked and aligned to national development visions generally delineated in Perspective Plan (2010-2021) and Sixth Five-Year Plan (2010-2015).

\section{MTBF Objectives}

The purpose of introduction of MTBF is to have a professional shift from traditional and rule-bound compliance-based budgetary process to performance-based budgetary process. Achieving the desired level of fiscal efficiency by utilizing the limited financial resources of the government is the main philosophy of MTBF. However, for a better understanding of the philosophy of MTBF, the following objectives have been set out:

a) To institutionalize a systematic framework for managing annual budget extended to a period of medium-term (4 years with 3 years projections);

b) To ensure the allocation of government's financial resources on the basis of strategic priorities of government; 


\section{Macrothink}

Journal of Public Administration and Governance

c) To empower line ministries through developing institutional and management capacity for preparing and managing their budgets effectively by themselves, and by this way ensure operational efficiency of implementing agencies;

d) To ensure the macroeconomic and fiscal stability of the economy through mobilizing, allocating and aligning financial resources of government around the articulated policy objectives.

\section{Reasons for Implementing MTBF in Bangladesh}

The traditional budget mechanism was highly centralized and all most all budgetary decisions were taken by Finance Division. Under the traditional system, the line ministry used to place only the annual financial requirements on the basis of incremental practice. They have very limited chance to take fruitful budgetary decisions rather they were frequently asked for under-appropriation of last year's allocation. The traditional budget had no scope to link financial allocation with strategic priorities of the government. Rather it was confined into performing only annual activities of ministries and agencies with a piecemeal type of decision. Like other 109 economies (World Bank, 2013) of the world, Bangladesh introduced MTBF in 2004 and piloted the process for FY 2005-2006 in four ministries successfully. From the FY 2011-12 MTBF has already been rolled out to all ministries and agencies of Bangladesh.

\section{MTBF and Fiscal Efficiency}

The medium Term Budgetary Framework is expected to enhance three types of fiscal efficiency like fiscal discipline, allocative efficiency, and operational efficiency. A detailed discussion on this issue has done below:

\subsection{Fiscal Discipline}

The tool of ensuring fiscal discipline under MTBF is Medium-Term Macroeconomic Framework. A Working Group comprising officials from Planning Commission, Economic Relation Division, Bureau of Statistics, National Board of Revenue (NBR), Bangladesh Bank, and other concerned officials from selective organizations prepares a draft Medium-Term Macroeconomic Framework and place it before the Honorable Minister of Finance for his approval. For ensuring fiscal discipline the 'working group' checks and forecasts GDP growth, the pattern of public sector investment, trend of revenue income, size of the budget deficit, borrowing sources etc. and then Finance Division determines ministry-wise probable resource ceiling for the medium term. The expenditure ceiling for line ministries are revised on the basis of three factors;

a) Total expenditure limit as projected in the macroeconomic framework;

b) Articulated strategic goals (vision, mission, and objectives) and medium-term targets as set out for particular ministry in Five Year's Development Plan of the country; and

c) Funding requirement of running projects and programs of line ministries. 


\subsection{Allocative Efficiency}

Allocative efficiency looks after the volatility of composition of public spending. When spending decisions and resource allocations are taken on the basis of strategic priorities with a long-term focus then volatility in the composition of spending would likely to be lessened (World Bank, 2013). In allocating process of financial resource, the ministry is asked to formulate their strategic goals and priorities on the basis of Five Year's Development Plan and accordingly articulate outcome indicators for the period of medium Term. Consequently, the line ministry is further asked to align and adjust the resource envelope in order to obtain estimated outcome targets. In this way MTBF checks the following issues of inefficiency which were in existence in the traditional budgetary process:

a) Checks allocation to non-prioritized areas;

b) Checks block allocation which is not defined;

c) Reduce discretion to allocate piecemeal basis, and finally

d) Minimize uncertainty of allocation streams for a medium term.

\subsection{Enhancing Operational Efficiency}

a) Operational efficiency is the issue which dealing with activity level which is being managed in agency level. The focus of operational efficiency is generating an output according to KPI standard through managing operations of the organization. The rule is 'maximize output with a minimum of resource'.

b) Under the MTBF, three factors of performance are considered seriously for ensuring Value for Money (VFM). Those are EEE - Economy, Efficiency, and Effectiveness. For ensuring "Economy" the focus is to be given on minimizing the cost of inputs for maximizing outputs. For ensuring "Efficiency" the focus is to be given on maximizing output-input ratio by producing maximum output using a minimum of the resource as possible. "Effectiveness" ensures that the outputs being delivered are essentials for achieving the strategic objectives of the organization.

c) For ensuring 'effectiveness' a set of measurable key performance indicators (KPIs) has to be identified in implementing agency linking strategic priorities articulated in Five Year's Development Plan and in ministry's medium-term outcome targets.

d) The policy is being linked to resource allocation and resource allocation is being linked to performance criteria.

e) As a follow-up mechanism, the government already started 'entity accounting' and 'entity auditing'. It is a radical shift from traditional accounting and auditing practice to performance-based accounting and auditing.

f) Under the process of MTBF, parliamentary oversight is being enhanced \& sharpened. 


\section{Approaches Used in Linking Strategy and Resource}

MTBF in Bangladesh has devised two phases in the budget formulation process for establishing an effective linkage between government policies and strategic priorities with resource allocation.

\subsection{The Strategic Phase}

Under the Budget Call Circular-1, the line ministries outline strategic objectives in terms of outcome, output and KPIs on the basis of indicative resource ceiling.

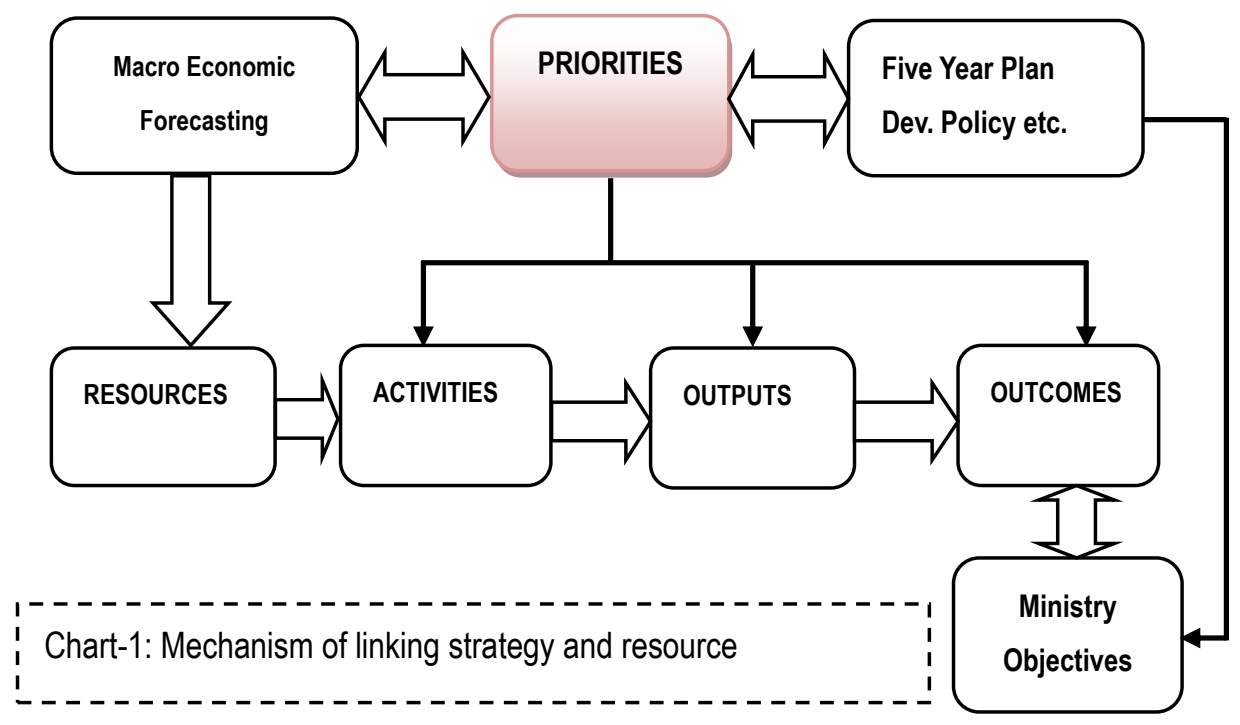

The line ministries are advised to formulate and articulate their mission statements and submit it to Finance Ministry. In order to formulate a valid and consistent vision and mission statement, the line ministry must have to go with a rigorous exercise on the Perspective Plan, 5-year Plan, own mandate and policy priorities etc. The respective subordinate organizations under the line ministries are also asked to formulate and articulate their own mission, medium-term objectives and activities aligning goals of own ministry.

\subsection{The Budget Estimation Phase}

Under the Budget Call Circular-2, the line-ministry works out an exercise on a detailed allocation of resources within the resource ceiling. In this respect, the line ministries are advised to place resource demand against outcome targets and KPIs articulated in BCC-1 document.

\section{Institutional Arrangement for Implementing Budget under MTBF}

Other than the constitutional provision, there was no legal and institutional framework for management of the public fund in Bangladesh. In pursuance of Financial Management Reform Program (FMRP), the government enacted 'The Public Fund and Budget Management Act 2009' for ensuring efficient management of the public fund and effective implementation of the budget. The other objectives of 'The Public Fund and Budget Management Act 2009' are to ensure transparency and accountability, to maintain fiscal 
stability, to manage deficit and public borrowings prudently etc. The Act narrates necessary support structures and guidelines for the smooth functioning of these structures. The Act also delineates two important committees in line ministry level for formulating, implementing and monitoring of budgetary process:

a) Budget Management Committees (BMCs) and Budget Working Groups established in all ministries and divisions and their subordinate departments.

b) Budget Management Committees (BWGs) of the line ministries, in consultation with the BWGs of subordinate offices, prepare Ministry Budget Framework linking strategic priorities of policies to resource allocation and linking resource allocation to key performance indicators (KPIs) and submit it to the Budget Management Committees (BMCs) for approval.

c) After approval of the BMCs, the Budget Frameworks of the line ministries are sent to Finance Division and Planning Commission(GoB, 2009).

\section{MTBF and Empirical Evidences of Better Fiscal Efficiency}

As a part of World Bank study (2012) on worldwide MTEF adoptions during 1990-2008 found a significant improvement of fiscal discipline as well as allocative efficiency. On a panel of 181 countries, the study also revealed a positive and significant improvement in technical efficiency (operational efficiency) (Grigoli et al. 2012).

Another World Bank study report concluded the following findings of the performance of MTBF across the 110 countries (Grigoli et al. 2012) of the world:

a) MTEF adoption has a significant positive effect on fiscal discipline (Grigoli et al. p. 47);

b) Fiscal balance improved in countries that implemented MTEF than in those that did not (Grigoli et al. p.47);

c) The marginal impact of MTPF (compared to an MTBF) is considerably larger (p.47);

d) MTEF adoption also has a payoff in terms of allocative efficiency (Grigoli et al. p.49);

e) Total expenditure volatility found declined and showed stronger moving to an MTBF and then to an MTPF (Grigoli et al. p.49);

f) The quality of budgeting has changed in terms of fiscal performance (Grigoli et al. p.50), and finally

g) The most common claim about MTEF is that it made the budget more strategic, increased the recognition of resource constraints, fostered cooperation between agencies, and improved fiscal discipline (Grigoli et al. p.52).

Uganda introduced MTEF in 1999 who is one of the countries who introduced MTEF at the second phase in the world. A review report (ODI, 2003) on MTEF evaluation of ten year's performance of Uganda concluded that Uganda has experienced sustainable and rapid growth, 
improvement of performance of public services and institutional capacities.

A UNESCO review on E-MTEF (Education-MTEF) in Nepal depicts a significant achievement of the education sector because of the introduction of MTEF. The report categorically mentioned that targets in 8 of 11 key indicators have been met or exceeded (p.24).

Another UNESCO review report on MTBF performance on education sector of nine Asian countries opined that it has helped to mobilize effective donor fund and minimized resource gap in this sector (UNESCO, 2010, p.27). The report also opined that as a result of the introduction of MTBF, countries like Nepal and Viet Nam successfully increased the share of allocation in education during the FY 2001-2004 (UNESCO, 2010, p.27).

In a draft review paper jointly prepared by ERD of Finance Ministry of Bangladesh and ESCAP (2010), it is found that fiscal performance has significantly improved over the period of 2006 to 2012. The report concluded that despite the effect of global economic slowdown and natural calamities like flood, cyclone and Sidre Bangladesh has successfully managed its steady growth, revenue income, budget deficit, public and private investment etc. (p.4).

The empirical evidence suggests that MTBF is instrumental in achieving the main objectives of the budget mechanism specifically for obtaining aggregate fiscal discipline (Brumby, et al. p.234). MTBF also have significant contribution in improving budget allocation in a prudent way which ensures value for money (Brumby, et al. p.234). There is a clear evidence of improving fiscal discipline and operational efficiency while adopting MTBF by many economies of the world.

\section{Conclusion}

Every approach may have merits and demerits. Theoretically, MTBF could be validated as Mixed Scanning Approach of decision-making. The basic assumption of MTBF is to formulate government budget beyond incremental practice. The incremental way of decision-making in preparation of the budget is not a problem only in Bangladesh rather it is a real problem for almost all the economies of the world. Both incrementalism and rationalism are extreme types of policy-making styles. In order to overcome the limitations of both the styles, Amitai Etzioni (1967) proposed Mixed Scanning Approach of decision-making. Because of its mixed scanning fashion, the Medium-term budgetary framework may be considered as one of the practices of Mixed Scanning Approach. Under the process of MTBF, the current-year budget is prepared after scanning the reality through the short-ranged lens while three-year future projections and forward estimates are being done using the long-ranged lens.

Under this approach, the countries concerned have ensured a significant level of efficiency and fiscal discipline but at the end of the day, the MTBF approach is also regarded as incremental. So, this approach has also failed to solve the limitations of incrementalism rather it is seen as the institutionalization of incrementalism in the name of MTBF or MTEF (UNESCO, 2009). 


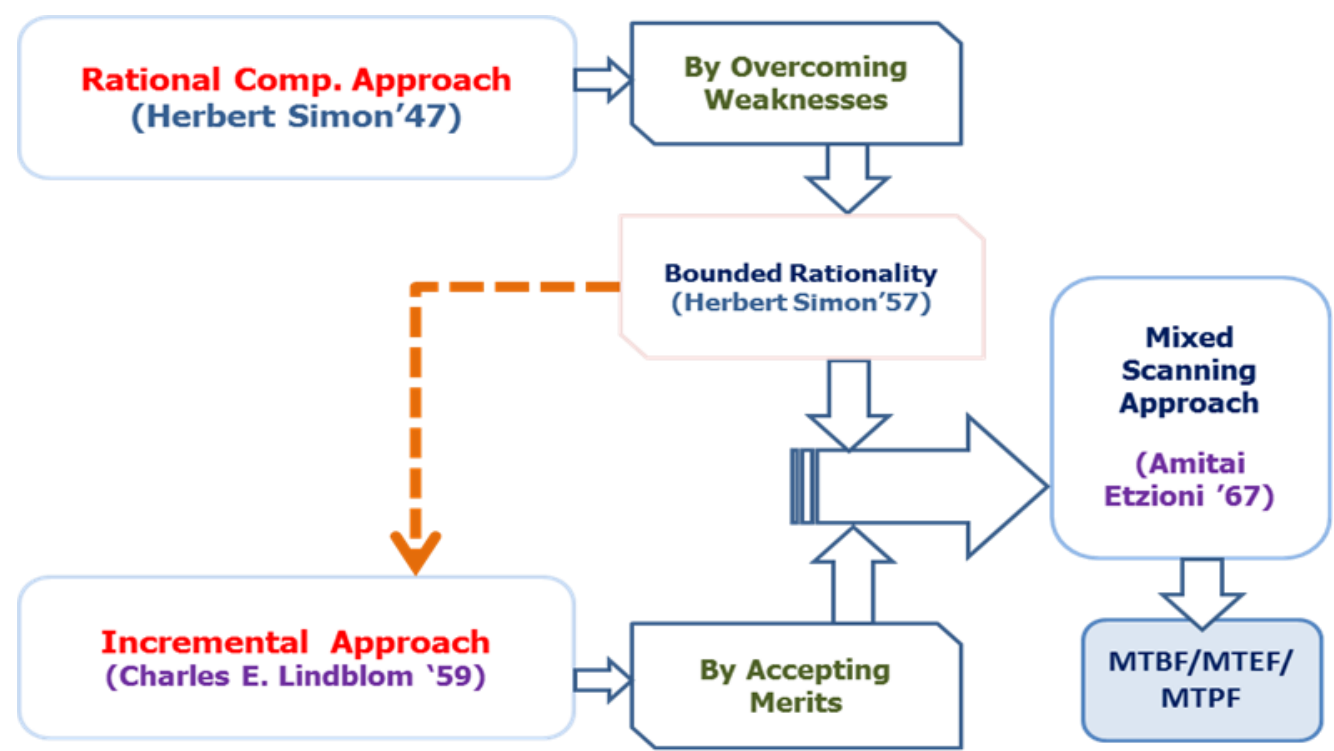

Figure 1. Mixed-Scanning Approach for Budgetary Decision-making

Moreover, while reviewing Budget Framework, it has been observed that in some cases, guidelines and directions that were provided to line ministries (in the Budget Circular 1) in terms of sectoral strategies, policies, and priorities were not properly reflected in line ministries' Budget Framework.

The MBF must demonstrate consistency with the strategic goals, policies, and priorities that have been identified in $6^{\text {th }}$ Five Year Plan and/or ministry relevant sectoral policies and also establishes an effective link between government's strategic goals, policies and priorities with budget allocations. It was also observed that the concept of linking sectoral strategies, policies, and priorities with expenditure allocation was not clear to the line ministries.

Under these circumstances, with the objective of removing the weaknesses of the Budget Framework, the capacity of the officials of the Finance Division, relevant ministries, and the Planning Commission must be developed. The institutional mechanism under MTBF must be made functional and sustained.

\section{Acknowledgement}

[The Paper was presented in Fourth International Conference on Advancement of Development Administration, 2015 (May 28-30) organized by NIDA, Thailand and revised subsequently on the observations of discussants. Thanks and gratitude to Dr. Nisada Wedchayanon, Professor, GSPA, NIDA, Bangkok for her kind advice and continuous guidance to perform the study.]

\section{References}

Bangkok, U. N. E. S. C. O. (2009). Education Financial Planning in Asia: Implementing Medium-Term Expenditure Frameworks Thailand

Brumby, J., \& Hemming, R. (2013). Medium-Term Expenditure Frameworks. In The International Handbook of Public Financial Management (pp. 219-236). Palgrave Macmillan, London. https://doi.org/10.1057/9781137315304_11 


\section{Macrothink}

Journal of Public Administration and Governance ISSN 2161-7104 2018, Vol. 8, No. 4

ESCAP and ERD. (2010). Implementation in Asia and the Pacific of the Brussels Programme of Action for the Least Developed Countries for the Decade 2001-2010: progress made, obstacles encountered and the way forward (DRAFT COUNTRY REVIEW PAPER), ESCAP and ERD, Ministry of Finance, Government of Bangladesh, High-level Asia-Pacific Policy Dialogue on the Brussels Programme of Action for the Least Developed Countries, 18-20 January 2010, Dhaka, Bangladesh

Etzioni, A. (1967). Mixed Scanning: A 'Third' Approach to Decision-Making. Public Administration Review, 27(5), 385-391. Print. https://doi.org/10.2307/973394

GoB. The Public Fund and Budget Management Act 2009, Pub. L. No. 40/2009, D A-1 5503 (2009). Bangladesh.

Grigoli, F., Mills, Z., Verhoeven, M., \& Vlaicu, R. (2012). MTEFs and fiscal performance: panel data evidence. The World Bank. The government of Bangladesh. (2009). The Public Fund and Budget Management Act 2009. https://doi.org/10.1596/1813-9450-6186

Holmes, M., \& Evans, A. (2003). A review of experience in implementing Medium Term Expenditure Frameworks in a PRSP context: a synthesis of eight country studies. London: Overseas Development Institute.

Ministry of Finance. (2005. Medium Term Budgetary Framework: 2005/06-2007/08. Finance Division, Government of the People's Republic of Bangladesh

World Bank. (2013). Beyond the Annual Budget. Washington, DC: World Bank. doi:10.1596/978-0-8213-9625-4 License: Creative Commons Attribution CC BY 3.0. https://doi.org/10.1596/978-0-8213-9625-4

UNESCO (2010). Education MTEF: Experience and Lessons from Nine Countries in Asia. Bangkok. Asia and Pacific Regional Bureau for Education Mom Luang Pin Malakul Centenary Building. 920 Sukhumvit Road, Prakanong, Klongtoey, Bangkok 10110, Thailand

Wagley, M. P., Lamichhane, S., \& Dhakal, T. (2010). Education financial planning in Asia: implementing medium-term expenditure frameworks: Nepal.

\section{Copyright Disclaimer}

Copyright for this article is retained by the author(s), with first publication rights granted to the journal.

This is an open-access article distributed under the terms and conditions of the Creative Commons Attribution license (http://creativecommons.org/licenses/by/4.0/). 